\title{
An Outdoor Mobile-Based Assessment Activity: Measuring Students' Motivation and Acceptance
}

\author{
http://dx.doi.org/10.3991/ijim.v10i4.5541 \\ Stavros A. Nikou and Anastasios A. Economides \\ University of Macedonia, Thessaloniki, Greece
}

\begin{abstract}
Mobile-devices are able to support a wide range of outdoor assessment activities. While there is a significant amount of research that investigates the acceptance of computer-based assessment from one side and the acceptance of mobile learning from the other, relatively few studies focus explicitly on the factors that influence the acceptance of Mobile-based Assessment. The current study implements a mobile-based outdoor educational activity in the city's Botanic Gardens during an environmental education project. 50 secondary school students participated in a mobileassisted assessment procedure using Quick Response (QR) coding technology through their mobile devices. The study examines the impact of Perceived Mobility, Authentic Context and Interest/Enjoyment on students' Perceived Usefulness, Perceived Ease of Use and Behavioral Intention to Use Mobile-based Assessment. Partial Least Squares (PLS) was used for the data analysis. Results show that Perceived Mobility, Authentic Context and Interest/Enjoyment, Perceived Usefulness and Perceived Ease of Use are all significant determinants of Behavioral Intention to Use mobilebased assessment. Furthermore, the study examines the impact of using mobile devices during the learning activity on students' learning motivation. Implications for designing and implementing mobile-based assessment procedures are discussed.
\end{abstract}

Index Terms - mobile-based assessment, mobile learning, motivation, technology acceptance model

\section{INTRODUCTION}

Mobile devices are becoming increasingly popular in education. They offer the potential to transform traditional educational practices by making learning more interactive, engaging and independent from timing and location constraints, maximizing the benefits for students, teachers and administrators [1].

Mobile devices have also the ability to support different assessment strategies, i.e. formative or summative assessments, self- or peer-assessment, adaptive, contextaware, game-based assessment. Mobile-based assessment can either be part of a pure mobile- learning curriculum or part of a blended educational approach complementing other traditional or web-based educational practices. Mobile devices can be used for assessment purposes inside the classroom boundaries, e.g. polling devices [2] or beyond, in context-aware ubiquitous learning activities [3]. They have been already used in a wide variety of educational settings, e.g. language teaching and learning [4], learning in museums [5], remote and virtual labs [6] and environmental education $[7,8,9]$.

In order for a mobile-based assessment strategy to be implemented successfully, it is necessary to investigate the factors that influence its adoption from the learning community. The current study fills a gap in the literature about student's acceptance of mobile-based assessment. It addresses also the positive impact that this kind of outdoor learning and assessment activity has on students' motivation.

The study is organized as follows. In the next section, we briefly introduce the issue of technology adoption from the perspective of Technology Acceptance Model and make a quick reference to Self Determination Theory of Motivation. Then, the proposed research model with our hypotheses is presented. Methodology section follows with participants, description of the conducted experiment and the instruments used. Data analysis comes afterwards. Thereafter, results are discussed as well as conclusions are presented.

\section{BACKGROUND}

Technology Acceptance Model (TAM) is one valid and well-established information systems theory that models how users accept and use technology [10]. TAM successfully explains and predicts the adoption of different educational technologies. Many studies use TAM as a framework to explain and predict student's acceptance of mobile learning $[11,12]$. Also there is a considerable amount of research about computer-based assessment adoption $[13,14,15]$. However, there is a gap in the literature about the adoption of Mobile-based Assessment. The current study is focusing on mobile-based assessment acceptance using a motivational perspective as well.

In TAM, behavioral intention to use is influenced by attitudes toward use, as well as the direct and indirect effects of perceived usefulness and perceived ease of use. Since its first introduction, TAM has been modified and extended to include additional variables in order to improve its predictive power. Researchers argue that mlearning users may have different roles (technology users, consumer and learners) [16]. Therefore different factors driving mobile learning adoption should be incorporated in an extended TAM model.

Mobility is perceived to be the most significant feature of mobile devices [17]. Our model introduces perceived mobility, as an external TAM variable, from the point of view of technology user.

Furthermore, the mobility feature of these devices enables "anywhere and anytime" learning in authentic contexts. The current study, implemented as an outdoor educational activity, introduces the role of authentic context in the adoption of a mobile-based assessment activity performed in the field, beyond the classroom boundaries.

Many researchers [18, 19] claim that, since TAM is primarily concerned with extrinsic motivations (conceptualized as perceived usefulness), its predictive power is 
limited to utilitarian systems (which are mainly productivity oriented). The same researchers argue that the role of intrinsic motivations is usually underestimated. According to Self-Determination Theory (SDT) by Ryan and Deci [20], intrinsic motivation (in contrast to extrinsic motivation) is the type of motivation that leads to a behavior that is inherently interesting and pleasant and it is this type of motivation that yields more positive outcomes. Students learn better when they are intrinsically motivated. Intrinsic motivation can be conceptualized as perceived interest and enjoyment. Previous research [21, 22] introduced intrinsic motivational factors into the mobile-based assessment adoption research. The current study examines the effect of interest/enjoyment (as a form of intrinsic motivation) on the students' intention to use mobile-based assessment in an outdoor assessment activity.

SDT proposes that the satisfaction of three basic psychological needs for autonomy, competence and relatedness, leads to internalization of extrinsic motivation and to intrinsic motivation [20]. In the footsteps of SDT, the current study investigates the issue of satisfaction of the three basic psychological needs (autonomy, competence and relatedness) during an outdoor mobile-based assessment activity.

\section{RESEARCH MODEL AND HYPOTHESES}

The current study uses the Technology Acceptance Model (TAM) [10] as a theoretical framework to investigate driving factors that influence mobile-based assessment acceptance. TAM is based on the constructs of Perceived Usefulness (PU) and Perceived Ease of Use (PEOU) and explains and predicts Behavioral Intention to Use (BIU) information systems. Perceived Usefulness (PU) is defined as "the degree to which a person believes that using a particular system will enhance his/her job performance" [10]. Perceived Ease of Use (PEOU) is defined as "the degree to which a person believes that using the system would be free of effort" [10].

Our model, spinning-off the basic TAM structure [10], proposes the following hypotheses about mobile-based assessment adoption:

H1a: Perceived Ease of Use (PEOU) has a positive effect on Perceived Usefulness (PU).

$\mathrm{H} 1 \mathrm{~b}$ : Perceived Ease of Use (PEOU) has a positive effect on Behavioral Intention to Use (BIU).

$\mathrm{H}$ 2: Perceived Usefulness (PU) has a positive effect on Behavioral Intention to Use (BIU).

A considerable number of external variables have been added so far to the basic TAM model, in order to improve its predictive power. Mobile - based assessment acceptance has been studied from the perspective of SelfDetermination theory of Motivation [21, 22]. Also, [23] examined the role of Personal Innovativeness and Previous Experience in the acceptance of mobile-based assessment. The current study, based on [24] introduces the constructs of Perceived Mobility (PM), Authentic Context (AC) and Interest/Enjoyment (IE) in an outdoor learning and assessment activity in the city's botanic garden. This study investigates how these factors contribute to the user's perception of how easy mobile-based assessment is, how useful it is and the degree of the students' intention to use the system.

Perceived mobility (portability) is defined as "the extent of user awareness of the mobility value of mobile services and systems" [25]. Users, who perceive the value of mobility, appreciate the ubiquity of mobile learning and have a strong perception of its usefulness. Previous research shows that perceived mobility significantly impacts perceived usability and perspectives of users toward mobile services $[25,26]$. Also, the mobility value compensates the technical limitations of mobile devices (e.g. screen size, low battery life) by enabling users to access information anytime and anywhere and enhancing this way users' acceptance of mobile services during mobilebased learning and assessment.

Therefore, we hypothesize that:

H3a: Perceived Mobility (PM) has a positive effect on Perceived Usefulness (PU).

H3b: Perceived Mobility (PM) has a positive effect on Perceived Ease of Use (PEOU).

We argue that perceived enjoyment will be a key factor of the students' learning experience and it will positively influence their interest in the activity. According to the Self Determination Theory of Motivation, Interest and Enjoyment is one dimension of intrinsic motivation. Previous studies have shown that perceived enjoyment with a particular service positively affects the intention of users to use the service on an ongoing basis [27]. Also, new technologies that are considered enjoyable and interesting are less likely to be difficult to use and satisfaction seems to correlates with the users' positive attitudes. Thus we hypothesize:

H4a: Interest/Enjoyment (IE) has a positive effect on Perceived Ease of Use (PEOU).

H4b: Interest/Enjoyment (IE) has a positive effect on Behavioral Intention to Use (BIU).

In [28], context is defined to consist of the Learner state, the Educational Activity state, the Infrastructure state and the Environment state. The current study considers only the environmental state (e.g. location, sensory data). Furthermore, authenticity is one dimension of a ubiquitous learning evaluation model proposed by [29]. Our study introduces the variable of Authentic Context (AC) in the investigation of the acceptance of mobilebased assessment. Authentic Context refers to the context awareness of a situated instructional activity. Students use the questions of the mobile-based assessment in order to observe the real objects and answer specific object-related questions. Therefore, we argue that the authentic context facilitates the assessment procedure. Furthermore, since assessment questions are contextualized and assess students' capability to apply knowledge and skills to real-life situations, we argue that mobile-based assessment in an authentic context is perceived as a useful activity that enhances learner's tasks. We also argue that the authentic context variable will have direct effect on behavioral intention to use.

Thus we hypothesize:

H5a: Authentic Context (AC) has a positive effect on Perceived Usefulness (PU).

H5b: Authentic Context (AC) has a positive effect on Perceived Behavioral Intention to Use (BIU).

H5c: Authentic Context (AC) has a positive effect on Perceived Ease of Use (PEOU).

The research model and all the hypotheses proposed in our model are depicted in Figure 1. 


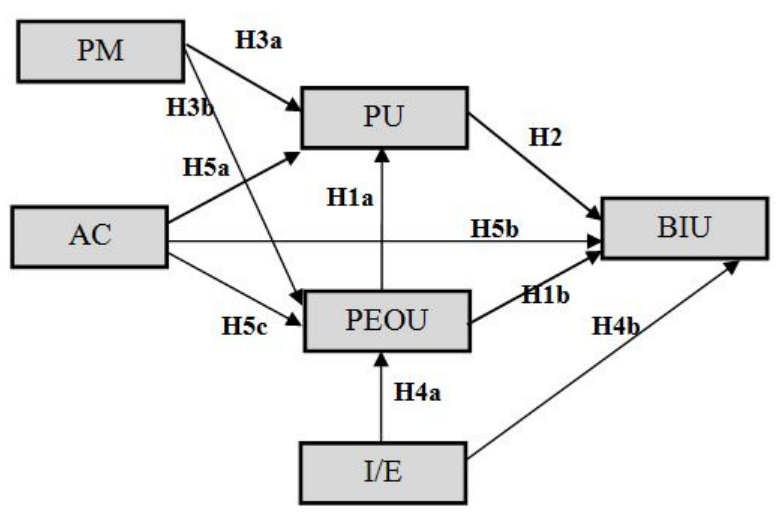

Figure 1. The proposed research model.

\section{METHODOLOGY}

\section{A. Participants}

The participants in the current study were 50 students from a Greek upper secondary school with their average age to be 16 years and two months $(\mathrm{SD}=1.02)$. There were 23 males $(46 \%)$ and 27 females $(54 \%)$. They were all enrolled in an environmental education project-based course about biodiversity. Since the use of mobile devices in the Greek educational settings is very limited, students had never used their mobile devices into a mobile learning activity so far. However, all students self- reported to be confident enough to use their smartphones to answer the questions during the assessment activity. Their median mobile self-efficacy score (questionnaire adopted from [30]) was 88 out of 100 .

\section{B. Procedure}

The learning environment was the city's botanic garden. The main educational activity was a mobile-based assessment procedure in the context of a project-based course about Environmental Education focusing on biodiversity. The aim of the learning activity was to motivate students to observe the plants in the botanic garden and to familiarize themselves with the plants' special characteristics (including plants' morphology, taxonomy, usage and their role in the biodiversity). Students followed a tour in the botanic garden. During the tour, students were asked to use their mobile devices in order to access supplemental material and questions about the observed plants (Figure 2).

Most students (95\%) used their smartphones while a few used their tablets (both equipped with camera and the appropriate Quick Response - QR application) to scan QR codes appropriately placed on the target plants under investigation. By scanning the QR codes, students were redirected each time to the appropriate web address with relevant learning content and questions about the plants under observation. The questions were all of multiplechoice type to facilitate data entry. Students prompted to answer the questions. Once students provided the questions the system provided the correct answers. After the learning activity, students were asked to respond to two survey questionnaires. The first questionnaire was about students' acceptance of the mobile-based assessment procedure. The second questionnaire was about students' learning motivation.

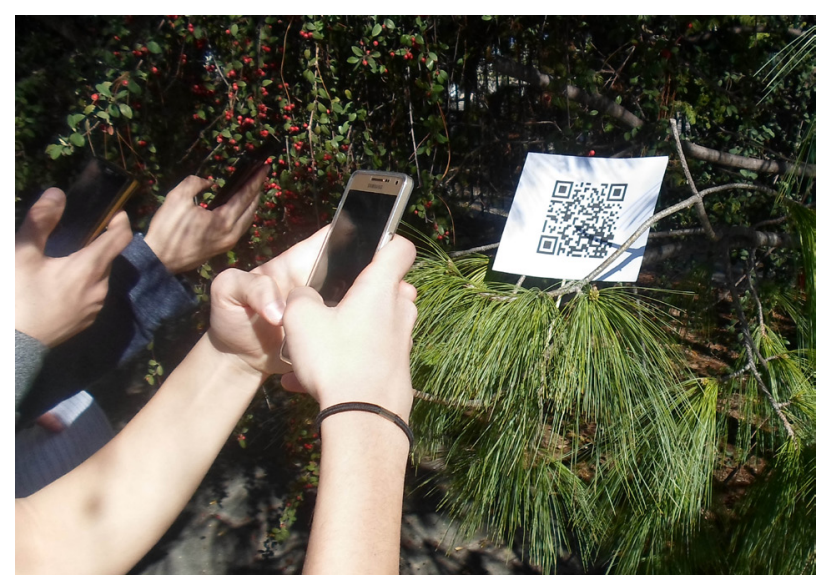

Figure 2. Mobile-based assessment outdoors

\section{Instrument}

In order to evaluate the Perceived Mobility, Authentic Context, Satisfaction, Perceived Usefulness and Perceived Ease of Use and Behavioral Intention to Use Mobilebased Assessment we have constructed a research instrument based on previous established questionnaires that were used and validated by other researchers. The questionnaire items used are described in Table V (Appendix). Items for Perceived Usefulness (PU), Perceived Ease of Use (PEOU) and Behavioral Intention to Use (BIU) were adopted from [10]. To assess Perceived Mobility (PM) we adopted items from [25]. For the Interest/Enjoyment (IE) we adopted the Interest/Enjoyment subscale from the Intrinsic Motivation Inventory [31, 32]. For Authentic Context (AC) we adopted items form [29]. Minor wording modifications of the items were made in order for them to describe the current research context (mobile-based assessment), i.e. the item "I intend to use e-learning in the future" was substituted by the item "I intend to use mobile devices for assessment purposes in the future".

According to the Self Determination Theory, motivation is mediated by the satisfaction of the basic needs of autonomy, competence and relatedness [20]. In order to evaluate the level of students' autonomy, competence and relatedness during the learning activity, we have used previously established and validated questionnaires. The items for autonomy and competence were adopted from $[33,34]$ and the items for relatedness were adopted from [19]. Proper wording modifications were made. The questionnaire items used are described in Table VI (Appendix). Both questionnaires were first developed in English and then a native bilingual speaker translated them into the Greek language. All items were measured using 7point Likert scales ranging from 1 (strongly disagree) to 7 (strongly agree).

\section{DATA ANALYSIS}

\section{A. Acceptance of Mobile-based assessment}

Partial Least-Squares (PLS) with Smart PLS 2.0 [35] was used as the analysis technique to predict factors influencing mobile-based assessment adoption. Our sample size exceeds the recommended value of 40 (10 times the largest number of independent variables impacting a depended variable).

Convergent and discriminant validity of the proposed research model need to be verified in order to ensure the quality of the model. Convergent validity is evaluated 
based on the following three criteria: (1) all the indicators factor loadings should exceed $0.7,(2)$ composite reliability of each construct should exceed 0.7 and (3) the average variance extracted (AVE) by each construct should exceed the variance due to measurement error for that construct (AVE > 0.5).

As table I shows, all criteria for convergent validity are satisfied: all factor loadings on their relative construct exceed 0.7 and all AVE values range from 0.594 to 0.644 $(A V E>0.5)$. Discriminant validity is supported when the square root of the average variance extracted (AVE) of a construct is higher than any correlation with another construct. Table II shows that all AVE square root values are greater than the intercorrelation values between constructs. Thus both convergent and discriminant validity for the proposed research model are verified.

Table III and Figure 3 summarize the structural model results. The figure shows the path coefficient for each path with its significance (as asterisks) and the $\mathrm{R}^{2}$ for each endogenous variable.

The model explains $29 \%$ of variance in Perceived Ease of Use $\left(\mathrm{R}^{2}=0.29\right), 37 \%$ in Perceived Usefulness $\left(\mathrm{R}^{2}=\right.$ $0.37)$ and $49 \%$ in Behavioral Intention to Use $\left(R^{2}=0.49\right)$.

TABLE I.

DESCRIPTIVE STATISTICS AND THE RESULTS FOR CONVERGENT VALIDITY FOR THE MEASUREMENT MODEL (ACCEPTED THRESHOLD VALUES IN BRACKETS)

\begin{tabular}{|c|c|c|c|c|c|}
\hline $\begin{array}{l}\text { Construct } \\
\text { Items }\end{array}$ & $\begin{array}{l}\text { Mean } \\
\text { (SD) }\end{array}$ & $\begin{array}{c}\text { Factor } \\
\text { Loading } \\
(>0.70)\end{array}$ & $\begin{array}{c}\text { Cron- } \\
\text { bach's a } \\
(>0.70)\end{array}$ & $\begin{array}{c}\text { Composite } \\
\text { Reliability } \\
\quad(>0.70)\end{array}$ & $\begin{array}{c}\text { Average } \\
\text { Variance } \\
\text { Extracted } \\
(>0.50) \\
\end{array}$ \\
\hline $\begin{array}{l}\text { Perceived } \\
\text { Ease of Use }\end{array}$ & $\begin{array}{c}5.79 \\
(0.88)\end{array}$ & & 0.841 & 0.711 & 0.644 \\
\hline PEOU1 & & 0.775 & & & \\
\hline PEOU2 & & 0.829 & & & \\
\hline $\begin{array}{l}\text { Perceived } \\
\text { Usefulness }\end{array}$ & $\begin{array}{c}4.77 \\
(1.29)\end{array}$ & & 0.714 & 0.760 & 0.612 \\
\hline PU1 & & 0.701 & & & \\
\hline PU2 & & 0.799 & & & \\
\hline PU3 & & 0.840 & & & \\
\hline $\begin{array}{l}\text { Perceived } \\
\text { Mobility }\end{array}$ & $\begin{array}{l}5.96 \\
(0.89)\end{array}$ & & 0.808 & 0.790 & 0.594 \\
\hline PM1 & & 0.767 & & & \\
\hline PM2 & & 0.812 & & & \\
\hline PM3 & & 0.731 & & & \\
\hline $\begin{array}{l}\text { Interest/ } \\
\text { Enjoyment }\end{array}$ & $\begin{array}{c}5.98 \\
(1.65)\end{array}$ & & 0.895 & 0.821 & 0.624 \\
\hline $\mathrm{I} / \mathrm{E} 1$ & & 0.897 & & & \\
\hline I/E2 & & 0.760 & & & \\
\hline I/E3 & & 0.701 & & & \\
\hline $\begin{array}{l}\text { Authentic } \\
\text { Context }\end{array}$ & $\begin{array}{c}6.01 \\
(1.22)\end{array}$ & & 0.764 & 8.670 & 0.636 \\
\hline $\mathrm{AC} 1$ & & 0.776 & & & \\
\hline $\mathrm{AC} 2$ & & 0.804 & & & \\
\hline $\mathrm{AC} 3$ & & 0.812 & & & \\
\hline $\begin{array}{l}\text { Behavioral } \\
\text { Intention to } \\
\text { Use }\end{array}$ & $\begin{array}{c}5.02 \\
(0.79)\end{array}$ & & 0.810 & 0.901 & 0.609 \\
\hline BIU1 & & 0.821 & & & \\
\hline BIU2 & & 0.720 & & & \\
\hline BIU3 & & 0.798 & & & \\
\hline
\end{tabular}

TABLE II.

DisCRIMINANT VALIDITY OF THE MOdel (VALues IN BolD: THE SQUARE RoOT OF THE AVERAGE VARIANCE EXTRACTED)

\begin{tabular}{lcclccc}
\hline Construct & PEOU & PU & PM & I/E & AC & BIU \\
\hline PEU & $\mathbf{0 . 8 0}$ & & & & & \\
PU & 0.55 & $\mathbf{0 . 7 8}$ & & & & \\
PM & 0.31 & 0.43 & $\mathbf{0 . 7 7}$ & & & \\
I/E & 0.45 & 0.51 & 0.45 & $\mathbf{0 . 7 9}$ & & \\
AC & 0.33 & 0.47 & 0.24 & 0.18 & $\mathbf{0 . 7 9}$ & \\
BIU & 0.24 & 0.29 & 0.69 & 0.39 & 0.22 & $\mathbf{0 . 7 8}$ \\
\hline Bold values: the square root of the average variance extracted (AVE) of each
\end{tabular}
construct.

TABLE III.

SUMMARY OF FINDINGS

\begin{tabular}{|l|l|c|c|}
\hline \multicolumn{1}{|c|}{ Hypothesis } & \multicolumn{1}{c|}{ Effect } & Coefficient & support \\
\hline H1a & PEOU $\rightarrow$ PU & $0.24^{* *}$ & yes \\
\hline H1b & PEOU $\rightarrow$ BIU & $0.35^{* *}$ & yes \\
\hline H2 & PU $\rightarrow$ BIU & $0.24^{* *}$ & yes \\
\hline H3a & PM $\rightarrow$ PU & $0.29^{* *}$ & yes \\
\hline H3b & PM $\rightarrow$ PEOU & $0.36^{* *}$ & yes \\
\hline H4a & I/E $\rightarrow$ PEOU & $0.22^{*}$ & yes \\
\hline H4b & I/E $\rightarrow$ BIU & $0.34^{* *}$ & yes \\
\hline H5a & AC $\rightarrow$ PU & $0.28^{* *}$ & yes \\
\hline H5b & AC $\rightarrow$ BIU & $0.21^{* *}$ & yes \\
\hline H5c & AC $\rightarrow$ PEOU & $0.32^{* * *}$ & yes \\
\hline${ }^{*} \mathrm{p}<.05,{ }^{* *} \mathrm{p}<.01,{ }^{* * *} \mathrm{p}<.001$. & \\
\hline
\end{tabular}

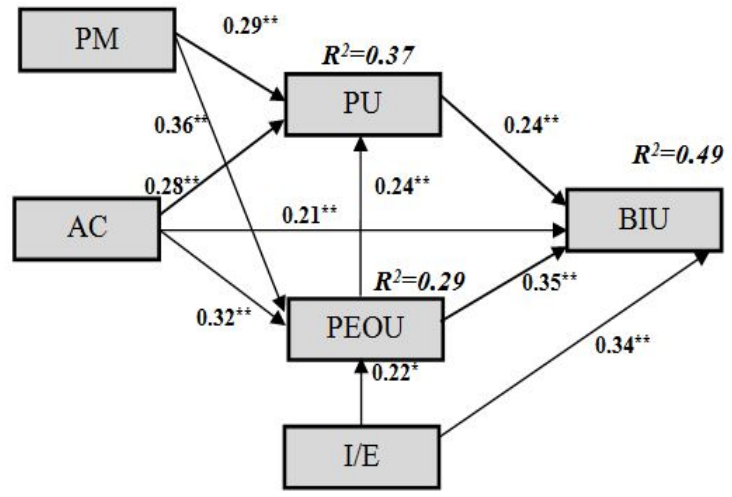

Figure 3. Result of the structural model.

\section{B. Motivational impact of the mobile-based assessment}

Descriptive statistics were calculated for each construct of the basic needs of the SDT: autonomy, competence and relatedness. The overall Cronbach's alpha for the each subscale was greater than 0.72 . Autonomy significantly correlates with both competence $(\mathrm{r}=0.32, \mathrm{p}<0.05)$ and relatedness $(\mathrm{r}=0.24, \mathrm{p}<0.05)$ and competence significantly correlates with relatedness $(\mathrm{r}=0.29, \mathrm{p}<0.05)$, confirming the validity of the questionnaire.

TABLE IV.

Descriptive Statistis For The SDT Basic Psychological NeEdS

\begin{tabular}{lllll}
\hline \multicolumn{1}{c}{ Basic Need } & & Mean & Std. Err. \\
\hline Autonomy & 5.64 & & 1.23 & \\
Competence & 5.97 & & 1.35 & \\
Relatedness & 5.21 & 1.58 & \\
\hline
\end{tabular}


From table IV, mean values are generally high. The findings show that the mobile-based learning and assessment activity provides a supportive environment for the satisfaction of the autonomy, competence and relatedness dimensions having the potential to enhance intrinsic motivation.

\section{RESULTS AND DISCUSSIONS}

To the best of our knowledge, the current study is one of the first ones investigating secondary students' attitudes and perceptions about the use of mobile devices in learning and assessment procedures during outdoor education in Greece,

stimulating a discussion about issues concerning the adoption of mobile-based assessment. The contribution of the study is twofold. First it contributes to the mobile learning acceptance research by focusing on mobile-based assessment adoption. Second it provides further evidence that mobile learning and assessment activities can support perceived autonomy, competence and relatedness and therefore enhance learning motivation.

\section{A. Acceptance of Mobile-based assessment}

The study shows that when mobile-based assessment is considered useful and easy to use, students are more likely to adopt it. Furthermore, the study extends the Technology Acceptance Model with the variables of Perceived Mobility, Authentic Context and Interest/Enjoyment. Perceived Mobility is the distinguished advantage of mobile learning over traditional forms of education. Mobile learners can access learning resources "anytime" and "anyplace" without any temporal and spatial limitations. This technological feature has a significant influence on user's attitudes and perceptions about mobile-based learning and assessment, which is in agreement with previous research [16]. Students appreciate the mobility feature that mobile devices offer during the educational activity outdoors. Therefore, Perceived Mobility significantly impacts user adoption of mobile-based assessment.

Our study shows that the construct of the authentic context enhances student acceptance of mobile learning and assessment. The notion of authentic learning tasks is considered one of the basic elements of new modes of assessment [36]. Mobile devices facilitate authentic learning tasks and make context-aware and ubiquitous learning and assessment a reality [1]. Furthermore, context-aware ubiquitous learning is capable of enhancing students' motivation and learning effectiveness [37] and can play a crucial role in the $21^{\text {st }}$ century learning.

The construct of Interest and Enjoyment provide a link between technology acceptance and motivation. Previous research has shown that enjoyment has a significant effect on behavioral intention to use mobile communication services [38]. The current study is in-line with previous research that extended TAM to include variables from Self-Determination Theory [21, 22]. Our findings provide evidence that Interest and Enjoyment have a significant effect on behavioral intention to use mobile-based assessment. Students are more willing to use a mobile-based assessment system that is interesting and enjoyable and thus intrinsically motivating. Interest/Enjoyment, as a hedonic variable, plays a critical role in the adoption of mobile-based assessment.

\section{B. Motivational impact of the mobile-based assessment}

Learning motivation is a key factor for student academic success and development [39]. Previous studies have examined the impact of mobile-based learning and assessment activities on students' motivation, performance and satisfaction, in outdoor educational settings e.g. botanic gardens [40]. Learning motivation, perceived learning performance and satisfaction seems to be higher for students participated in mobile-supported (compared to traditional paper-and-pencil) science inquiry educational activities. The current study is in-line with previous research. The outdoor mobile-assisted learning and assessment activity supports student intrinsic needs for perceived autonomy, competence and relatedness. When people experience greater satisfaction of the basic psychological needs for autonomy, competence and relatedness they are more autonomously motivated and engaged [41].

The results of the study can be valuable for researchers in the field of technology adoption, educational policy administrators, instructional designers and teachers as well.

Mobile technologies offer innovative ways that have the potential to enhance assessment if they build upon proper theoretical frameworks [28, 42, 43, 44]. Mobile devices can be used both inside and outside the classroom boundaries [45]. They also can be used not only in pure mobile learning curriculums but in blended learning approaches as well. Students like to use mobile devices for educational purposes [46] and feel more motivated when they use mobiles in their learning [47]. Therefore educational policy makers and instructional designers should promote and support the use of mobile devices for learning and assessment. More research on mobile-based assessment adoption is needed in order for mobile learning and assessment to be successfully implemented in different educational settings. It is in our research priorities to further investigate more variables that mediate the adoption of mobile-based assessment in different educational settings and also to investigate possible mobile learning and assessment practices that further enhance student motivation towards learning.

\section{ACKNOWLEDGMENT}

Authors would like to thank the Manager of the Botanic Gardens of Stavroupoli (Municipality of Pavlos Melas) for the support during the students' guided tour.

\section{REFERENCES}

[1] S. A. Nikou and A. A. Economides, "Mobile Assessment: State of the art", in Z. L. Berge and L. Y. Muilenburg (Eds.), Handbook of mobile learning, Florence, KY: Routledge, pp. 346-355, 2013.

[2] J. C.-Y. Sun, "Influence of polling technologies on student engagement: An analysis of student motivation, academic performance, and brainwave data", Computers \& Education, vol. 72, pp. 80-89, 2014. http://dx.doi.org/10.1016/j.compedu.2013.10.010

[3] G. J. Hwang and H.-F. Chang, "A formative assessment-based mobile learning approach to improving the learning attitudes and achievements of students", Computers \& Education, 56, 10231031, 2011. http://dx.doi.org/10.1016/j.compedu.2010.12.002

[4] C.-M. Chen and Y.-L. Li, "Personalised context-aware ubiquitous learning system for supporting effective English vocabulary learning". Interactive Learning Environments, vol. 18, no. 4, pp. 341364, 2010. http://dx.doi.org/10.1080/10494820802602329

[5] H.-T. Hou, S.-Y. Wu, P.-C. Lin, Y.-T. Sung, J.-W. Lin and K.-E. Chang, "A Blended Mobile Learning Environment for Museum Learning”, Educational Technology \& Society, 17 (2), 207-218, 2014 . 
[6] W. Rochadel, J. B. da Silva, J.P. Simão, G.R. Alves, R. Marcelino and V. Gruber, "Extending access to remote labs from mobile devices in educational contexts", International Journal of Online Engineering (iJOE), 9(S3), pp. 9-13, 2013. http://dx.doi.org/10.3991/ijoe.v9is3.2538

[7] Y.-M. Huang, Y.-T. Lin and S.-C. Cheng, "Effectiveness of a Mobile Plant Learning System in a science curriculum in Taiwanese elementary education", Computers \& Education, 54, 47-58, 2010. http://dx.doi.org/10.1016/j.compedu.2009.07.006

[8] Shih, J.-L., Chu, H.-C., Hwang, G.-J. and Kinshuk, "An investigation of attitudes of students and teachers about participating in a context-aware ubiquitous learning activity". British Journal of Educational Technology, vol. 42, pp. 373-394, 2011. http://dx.doi.org/10.1111/j.1467-8535.2009.01020.x

[9] A. Vasiliou and A.A.Economides, "Mobile collaborative learning using multicast MANETs", International Journal of Mobile Communications (IJMC), Vol. 5, No. 4, pp. 423-444, 2007. http://dx.doi.org/10.1504/IJMC.2007.012789

[10] F. D. Davis, "Perceived usefulness, perceived ease of use and user acceptance of information technology". MIS Quartely, vol. 13, no. 3, pp. 319-340, 1989. http://dx.doi.org/10.2307/249008

[11] A. A. Aish and S. Love, "Factors influencing students' acceptance of mlearning: An investigation in higher education". The International Review of Research in Open and Distance Learning, vol. 14, no. 5, pp. 82-107, 2013.

[12] S.Y. Park, M.-W. Nam and S.-B. Cha, "University students' behavioral intention to use mobile learning: Evaluating the technology acceptance model". British Journal of Educational Technology, vol. 43, no. 4, pp. 592-605, 2012. http://dx.doi.org/10.1111/j.1467-8535.2011.01229.x

[13] V. Terzis \& A.A. Economides. "The acceptance and use of computer based assessment”, Computers \& Education, vol. 56, no. 4, pp. 1032-1044, 2011. http://dx.doi.org/10.1016/j.compedu. 2010.11 .017

[14] V. Terzis and A.A. Economides, "Continuance acceptance of computer based assessment through the integration of user's expectations and perceptions", Computers \& Education, vol. 62, pp. 50-61, 2013. http://dx.doi.org/10.1016/j.compedu.2012.10.018

[15] V. Terzis, C. N. Moridis, A.A. Economides and G. RebolledoMendez, "Computer Based Assessment Acceptance: A Crosscultural Study in Greece and Mexico", Educational Technology \& Society, vol.16, no. 3 , pp. 411-424, 2013.

[16] Y. Liu, S. Han and H. Li, "Understanding the factors driving mlearning adoption: a literature review". Campus-Wide Information Systems, vol. 27, no. 4, pp. 210-226, 2010. http://dx.doi.org/10.1108/10650741011073761

[17] N. Mallat, M. Rossi, V.K. Tuunainen and A. Oorni, "The impact of use situation and mobility on the acceptance of mobile ticketing service", Proceedings of the 39th Hawaii International Conference on System Sciences, Hawaii, USA vol. 12, no. 1, pp. 57-65, 2006. http://dx.doi.org/10.1109/hicss.2006.472

[18] H. van der Heijden, "User acceptance of hedonic information systems", MIS Quarterly, 28(4), 695-702, 2004.

[19] J. C. Roca and M. Gagné, "Understanding e-learning continuance intention in the workplace: A self-determination theory perspective", Computers in Human Behavior, vol. 24, no. 4, pp. 15851604, 2008. http://dx.doi.org/10.1016/j.chb.2007.06.001

[20] E. L. Deci and R. M. Ryan, Intrinsic motivation and selfdetermination in human behavior, New York: Plenum, 1985. http://dx.doi.org/10.1007/978-1-4899-2271-7

[21] S.A. Nikou and A.A. Economides, "A model for Mobile-based Assessment adoption based on Self-Determination Theory of Motivation", International Conference on Interactive Mobile Communication Technologies and Learning (IEEE), pp.86-90, 13-14 Thessaloniki, Greece, November 2014. http://dx.doi.org/10.1109/ imctl.2014.7011111

[22] S.A. Nikou and A.A. Economides, "Acceptance of mobile-based assessment from the perspective of Self-Determination Theory of motivation", International Conference of Advanced Learning Technologies, pp.454- 458, IEEE ICALT 2014, Athens, 7-9 July 2014. http://dx.doi.org/10.1109/icalt.2014.136

[23] S.A. Nikou and A.A. Economides, "The role of personal innovativeness and previous experience in explaining and predicting mobile-based assessment adoption". In 19-22 Oct 2015.
[24] S.A Nikou and A.A. Economides, "The effects of perceived mobility and satisfaction on the adoption of mobile-based Assessment", 9th International Conference on Interactive Mobile Communication Technologies and Learning (IEEE), Thessaloniki, Greece, 19-20 November, 2015. http://dx.doi.org/10.1109/ imctl.2015.7359579

[25] J.J. Huang, Y.R. Lin and S.T. Chuang, "Elucidating user behavior of mobile learning: A perspective of the extended technology acceptance model", The Electronic Library, Vol. 25, Iss: 5, pp. 585 - 598, 2007. http://dx.doi.org/10.1108/02640470710829569

[26] E. Park and K.J. Kim, "User acceptance of long-term evolution (LTE) services: an application of extended technology acceptance model", Program: Electron. Lib. Info. Syst., 47 (2), 188-205, 2013. http://dx.doi.org/10.1108/00330331311313762

[27] E. Park, S. Baek, J. Ohm and H.C. Chang, "Determinants of player acceptance of mobile social network games: An application of extended technology acceptance model", Telematics and Informatics, vol. 31 pp.3-15, 2014. http://dx.doi.org/10.1016/j.tele. 2013.07.001

[28] A. A. Economides, "Adaptive context-aware pervasive and ubiquitous learning". International Journal of Technology Enhanced Learning, Vol. 1, No 3, pp. 169-192, Inderscience, 2009.

[29] Y. M. Huang, P.S. Chiu, T.C. Liu and T.S. Chen, "The design and implementation of a meaningful learning-based evaluation method for ubiquitous learning". Computers \& Education, vol 57, no. 4, pp. 2291-2302, 2011. http://dx.doi.org/10.1016/j.compedu. $\underline{2011.05 .023}$

[30] R. F. Kenny, J. M. V. Neste-Kenny, P.A. Burton, C. L. Park, and A. Qayyum, "Using self-efficacy to assess the readiness of nursing educators and students for mobile learning", The International Review of Research in Open and Distance Learning, vol. 13, no. 3, pp. 277-296, 2012.

[31] E. McAuley,T. Duncan, and V.V. Tammen, "Psychometric properties of the intrinsic motivation inventory in a competitive sport setting: A confirmatory factor analysis". Research Quarterly for Exercise and Sport, vol. 60,pp. 48-58, 1987. http://dx.doi.org/10.1080/02701367.1989.10607413

[32] R.M. Ryan and E.L. Deci, "Self-determination theory and the facilitation of intrinsic motivation, social development and wellbeing". American Psychologist, vol.55, pp. 68-78, 2000. http://dx.doi.org/10.1037/0003-066X.55.1.68

[33] R. Ryan, C.S. Rigby and A. Przybylski, "The motivational pull of video games: a self-determination theory approach". Motivation and Emotion, vol. 30, no.4, pp. 344-360, 2006. http://dx.doi.org/10.1007/s11031-006-9051-8

[34] Y.J. Kim and V.J. Shute, "The interplay of game elements with psychometric qualities, learning, and enjoyment in game-based assessment", Computers \& Education, vol. 87, pp. 340-356, 2015. http://dx.doi.org/10.1016/j.compedu.2015.07.009

[35] C.M. Ringle, S. Wende and A. Will, SmartPLS 2.0 (beta), [Computer Software], Retrieved from http://www.smartpls.de, 2005.

[36] M. Birenbaum and F. J. R. C. Dochy, "Alternatives in assessment of achievements, learning processes and prior knowledge", Boston, MA, Kluwer Academic Publishers, 1996. http://dx.doi.org/10.1007/978-94-011-0657-3

[37] J.-L. Shih, H.-C. Chu, G.-J. Hwang and Kinshuk, "An investigation of attitudes of students and teachers about participating in a context-aware ubiquitous learning activity". British Journal of Educational Technology, vol. 42, pp. 373-394, 2011. http://dx.doi.org/10.1111/j.1467-8535.2009.01020.x

[38] E. Park and A.P. del Pobil, "Modeling the user acceptance of long-term evolution services", Ann. Telecommun, vol.68, no.5, pp.307-415, 2013. http://dx.doi.org/10.1007/s12243-012-0324-9

[39] M. Hartnett, A. St George and J. Dron, "Being together: Factors that unintentionally undermine motivation". Journal of Open, Flexible, and Distance Learning, vol.15, no.1, pp.1-16, 2011.

[40] S.A. Nikou and A.A. Economides, "The impact of an outdoor mobile-supported learning activity on students' motivation, performance and satisfaction", In Crompton, H., Traxler, J. (Ed.), Mobile learning and STEM: Case studies in practice, Chapter 4, New York: Routledge, 2015.

[41] E.L. Deci and R.M. Ryan, "The importance of universal psychological needs for understanding motivation in the workplace". In M. Gagne, The Oxford handbook of work engagement, motivation, 
and self-determination theory (pp. 13-32). New York, NY: Oxford University Press, 2014.

[42] A. A. Economides, "Requirements of mobile learning applications", International Journal of Innovation and Learning, vol. 5, no. 5 , pp. 457-479, 2008. http://dx.doi.org/10.1504/IJIL. 2008.018043

[43] A. A. Economides, "Adaptive mobile learning", In Proceedings of the IEEE WMUTE- 4th International Workshop on Wireless, Mobile and Ubiquitous Technologies in Education, pp. 26-28, Athens, Greece, IEEE, 2006. http://dx.doi.org/10.1109/wmte.2006. 261339

[44] A. A. Economides, "Context-aware mobile learning", The Open Knowledge Society, A Computer Science and Information Systems Manifesto, First World Summit, WSKS 2008, Athens, Greece. Proceedings. Springer Communications in Computer and Information Science (CCIS) vol.19, pp. 213-220, 2008. http://dx.doi.org/10.1007/978-3-540-87783-7_27

[45] E. Triantafillou, E. Georgiadou and A. A. Economides, "CATMD: Computer adaptive test on mobile devices". In: MéndezVilas, A. Solano Martín, J.A. Mesa González and J. Mesa González (eds.), "Current Developments in Technology-Assisted Education (2006), Vol. II: Technological Science Education, Collaborative Learning, Knowledge Management", Proceedings of the IV International Conference on Multimedia and ICTs in Education (m-ICTE2006), pp. 773-777, 2006.

[46] A. A. Economides and A. Grousopoulou, "Mobiles in education: Students' usage, preferences and desires", International Journal of Mobile Learning and Organisation, vol. 4, vo. 3, pp. 235-252, 2010.

[47] S.A. Nikou and A.A. Economides, "The impact of paper-based, computer-based and mobile-based self-assessment on students' science motivation and achievement", Computers in Human Behavior, Vol. 55, Part B, February 2016, pp.1241-1248, 2016.

\section{AUTHORS}

Stavros A. Nikou (B.Sc. Physics - Aristotle University, Greece and M.Sc. Computer Science - University of Houston Clear Lake, USA) is a STEM Educator and Ph.D. student in the field of mobile learning at University of Macedonia (Interdepartmental Program of Postgraduate Studies in Information Systems), Greece. (email: stavrosnikou@sch.gr).

Anastasios A. Economides is a Professor on Computer Networks \& Telematics Applications at the University of Macedonia (Interdepartmental Program of Postgraduate Studies in Information Systems), Greece. He is the director of CONTA (COmputer Networks and Telematics Applications) Laboratory. He has published over two hundred (200) peer-reviewed papers on Computer Networks, E-Learning and other E-Services. (e-mail: economid@uom.gr).

This article is an extended and modified version of a paper presented at the International Conference on Interactive Mobile Communication, Technologies and Learning (IMCL2015), Special Session MsM'2015 "Motivating Students with Mobiles", held in November 2015, in Thessaloniki, Greece. Submitted 31 January 2016. Published as resubmitted by the authors 1 September 2016.

\section{APPENDIX}

TABLE V.

ACCEPTANCE QUESTIONNAIRE

\begin{tabular}{|c|c|c|c|}
\hline Constructs & Items & Descriptions & Sources \\
\hline \multirow{3}{*}{$\begin{array}{l}\text { Behavioural } \\
\text { Intention to } \\
\text { Use }\end{array}$} & BIU1 & I indent to use mobile devices for assessment purposes in the future. & \multirow{3}{*}{ Davis (1989) } \\
\hline & BIU2 & I plan to use mobile devices for assessment purposes in the future. & \\
\hline & BIU3 & I predict I would use mobile devices for assessment purposes in the future. & \\
\hline \multirow{3}{*}{$\begin{array}{l}\text { Perceived } \\
\text { Mobility }\end{array}$} & PM1 & It is convenient to access mobile-based assessment anywhere and anytime. & \multirow{3}{*}{ Huang et al. (2007) } \\
\hline & PM2 & Mobility is an outstanding advantage of mobile-based assessment. & \\
\hline & PM3 & Mobility makes it possible to get the real-time assessment data. & \\
\hline \multirow{3}{*}{$\begin{array}{l}\text { Authentic } \\
\text { Context }\end{array}$} & $\mathrm{AC1}$ & I can learn with authentic-environment related materials & \multirow{3}{*}{ Huang et al. (2011) } \\
\hline & $\mathrm{AC} 2$ & I can learn in an authentic environment & \\
\hline & AC3 & I can observe real learning objects & \\
\hline \multirow{3}{*}{$\begin{array}{l}\text { Interest/ } \\
\text { Enjoyment }\end{array}$} & $\mathrm{I} / \mathrm{E} 1$ & I enjoyed the learning \& assessment activity very much & \multirow{3}{*}{ Ryan \& Deci $(2000)$} \\
\hline & $\mathrm{I} / \mathrm{E} 2$ & Performing the learning $\&$ assessment activity was fun & \\
\hline & I/E3 & I would describe the learning $\&$ assessment activity as very interesting & \\
\hline \multirow{2}{*}{$\begin{array}{l}\text { Perceived } \\
\text { Ease of Use }\end{array}$} & PEOU1 & I find the mobile-based assessment easy to use. & \multirow{2}{*}{ Davis (1989) } \\
\hline & PEOU2 & Learning how to use the mobile-based system is easy for me. & \\
\hline \multirow{3}{*}{$\begin{array}{l}\text { Perceived } \\
\text { Usefulness }\end{array}$} & PU1 & I think mobile-based assessment is useful for my learning. & \multirow{3}{*}{ Davis (1989) } \\
\hline & PU2 & Using mobile-based assessment increases my productivity. & \\
\hline & PU3 & Using mobile-based assessment improves my performance and effectiveness in my learning & \\
\hline
\end{tabular}

TABLE VI.

BASIC PSYCHOLOGICAL NEEDS QUESTIONNAIRE

\begin{tabular}{|c|c|c|}
\hline Constructs & Descriptions & Sources \\
\hline \multirow{3}{*}{ Autonomy } & The mobile learning activity provided me with interesting options and choices. & \\
\hline & The mobile learning activity let me do interesting things. & Ryan et al. (2006) \\
\hline & I experienced freedom during the mobile learning activity. & \\
\hline \multirow{3}{*}{ Competence } & I felt competent during the mobile learning activity & \\
\hline & I felt very capable and effective when participating in the mobile learning activity & Kim \& Shute (2015) \\
\hline & My ability to participate in the mobile learning activity was well matched with the activity's challenges & \\
\hline \multirow{3}{*}{ Relatedness } & I felt connected with my classmates during the mobile learning activity & \\
\hline & I could work in teams during the mobile learning activity & Roca \& Gagné (2008) \\
\hline & During the mobile learning I felt valued by people who I think are significant & \\
\hline
\end{tabular}

